\title{
Load Securement and Packaging Methods to Reduce Risk of Damage and Personal Injury for Cargo Freight in Truck, Container and Intermodal Shipments
}

\author{
Sher Paul Singh \\ Packaging Forensic Associates, Inc. \\ packlawusa@gmail.com
}

Jay Singh

California Polytechnic State University jasingh@calpolv.edu

\author{
John Antle \\ ABF Freight System \\ jantle@abf.com \\ Erin Topper \\ National Motor Freight Transport Association \\ etopper@nmfta.org
}

\author{
G. Grewal \\ Packaging Research Associates Inc.
}

gsgmsu@yahoo.com

\begin{abstract}
This paper is the fourth paper in a series of papers that analyzed results from a major damage assessment study that examined challenges products endure during shipping and handling in the mixed-load and lessthan-truckload (LTL) logistics environments. The previous three papers are specific to various commodities, such as televisions, appliances, furniture, machinery, doors and windows, and paint products. These products are known to represent high levels of freight damage and corresponding claims to carriers. Products of different sizes and weights are loaded into trailers using various methods both mechanical and manual, by various algorithms to best weigh or cube out a trailer efficiently. However improper loading and lack of load securement inside the trailer can result in damage to both packages and the products they contain, and can lead to subsequent injury during unloading. The paper discusses improperly loaded trailers, and recommends proper loading methods. In addition choice of good pallets and unitization methods is discussed. It also presents US Department of Transportation (DOT) regulations to secure loads for transport. It also presents requirements to meet Federal Motor Carrier Safety Regulations (FMCSR).
\end{abstract}

Key Words: Packaging, Pallets; Loading and Unloading Methods; Less-Than-Truckload Shipments; Damage Reduction; Personal Injury; Freight Damage 


\subsection{INTRODUCTION}

Three previous research studies have specifically discussed packaging of major categories of commodities that are transported around the country via motor carriers, and are a subject of major damage due to improper packaging. This was based on a major survey done to collect information from leading less-than-truckload (LTL) carriers. These papers ${ }^{1,2,3}$ showed packaging deficiencies associated with appliances, furniture, televisions, hazardous materials such as paint, doors and windows. with appliances, furniture, televisions, hazardous materials such as paint, doors and windows. Carriers of all modes of transport (truck, rail, ship and air) are faced daily with the challenge of optimizing the available space in the logistical vehicle with the largest number of shipping units that can be shipped without causing damage and compromising safety. This is sometimes a difficult task if the carrier does not truly comprehend the protective capabilities and the integrity of packages that have been placed in shipment with other packages from other shippers, all moving within the same vehicle. The same applies if a shipper places packages of different sizes and weights inside a van or container that is to be moved by a carrier. The complexity increases as carriers develop intermodal transport solutions for their customers by using a combination of truck, rail, sea, and air modes to efficiently deliver packaged products economically in the global environment, while staying competitive.

Previous studies have measured and quantified the severity of both physical and climatic levels of various transportation systems and monitored packages in North America, South America, Europe and Asia, including inter-continental shipments $^{4-17}$. Based on these studies, international associations and professional societies like the American Society of Testing and Materials (ASTM), International Safe Transit Association
(ISTA), and International Standards Organization (ISO) have developed test methods to perform pre-shipment testing to simulate package testing to various elements that may include atmospheric and climatic conditioning, tip-over, shock and impact, transport vibration, manual and fork lift handling, low pressure and compression.

However these standards do not emphasize the probability of mixing different packaged products or palletized loads inside a logistical vehicle such as a truck-trailer, boxcar or ISO inter-modal container. Packaging requirements, for freight transported via LTL, are defined in the National Motor Freight Classification $(N M F C)^{18}$. Each commodity description in the NMFC specifies minimum packaging requirements to ensure the products can be handled and protected in the motor carrier environment. The descriptions may be as simple as "in boxes," "in drums," "in boxes, crates, or on a lift truck skid or pallet". The freight costs or tariff that is shown in the "Bill of Lading", which is a contract between the shipper and carrier, is based on "Freight Class". Freight Classes are determined by the National Motor Freight Traffic Association (NMFTA) ${ }^{18}$. There are seventeen freight classes, ranging from Class 50 to Class 500 , used by the NMFTA, based on the following four factors:

- Density

- Value

- Packaging

- Handling Characteristics

In general, higher the freight class, higher the shipping costs or tariff associated with that product. Historically, Class 50 would cost $50 \%$ of the shipping and handling costs associated with Class 100. Class 200 would be twice the cost of Class 100. However, nowadays carriers quote actual prices for a given class. These prices also accom- 
modate special handling requirements depending on the freight to be transported and handled. It is however the shipper's responsibility to develop packaging that meets the "minimum" requirements expected by the carrier based on the Classification, if that is agreed in the Bill of Lading. Any variation or exemptions can affect the claims if damage or an accident occurs in transit.

In trying to understand how packaging and different loading methods can affect damage claims, six LTL motor carriers were surveyed and asked questions regarding their company's practices. These results have been discussed specific to different commodities in the previous papers ${ }^{1-3}$. Proper loading methods, securement of load, blocking and bracing along with the packaging play a very important role in not only preventing damage to the products, but also facilitate in the safe handling and stowing of the products for carriers. This study contains pictures from shipments that depict the type of freight and packaging that is commonly seen in LTL and mixed load environments, and discusses methods to reduce damage and enhance safety.

\subsection{FEDERAL MOTOR CARRIER SAFETY REGULATIONS}

The paper first outlines the Code of Federal Regulations 49 (CFR 49) on Transportation, which is the required law to be met by all carriers, their equipment and operators, operating truck trailers in the United States to move freight ${ }^{19}$. In addition to these requirements of law, the shipping and packaging industry has developed industry accepted standards and practices to enhance these minimum rules and regulation(s) for handling and transportation of cargo or freight. It should be known that the CFR 49 and other applicable regulations are the minimum required.
Shippers, carriers, and manufacturers of package systems should provide additional safe means based on new research and information available to them to improve safety and stability of loads during transportation to prevent damage and injury.

The minimum required regulations are provided in $\$ 393$ of CFR 49 which is applicable to all commodities. Additional requirements for hazardous materials are described in $\S 171-\S 180$. With respect to inspection of cargo, cargo securement devices and systems, CFR $49 \S 392.9$ covers the inspection of cargo, cargo securement devices and systems. In this section it states in the general requirements that ${ }^{19}$ :

"A driver may not operate a commercial motor vehicle and a motor carrier may not require or permit a driver to operate a commercial motor vehicle unless:

(1) The commercial motor vehicle's cargo is properly distributed and adequately secured as specified in\$\$393.100 through 393.136 of this subchapter.

(2) The commercial motor vehicle's tailgate, tailboard, doors, tarpaulins, spare tire and other equipment used in its operation, and the means of fastening the commercial motor vehicle's cargo, are secured; and

(3) The commercial motor vehicle's cargo or any other object does not obscure the driver's view ahead or to the right or left sides (except for drivers of self-steer dollies), interfere with the free movement of his/her arms or legs, prevent his/her free and ready access to accessories required for emergencies, or prevent the free and ready exit of any person from the commercial motor vehicle's cab or driver's compartment."

It should be noted that the driver of the truck is required to inspect the cargo and the devices used 

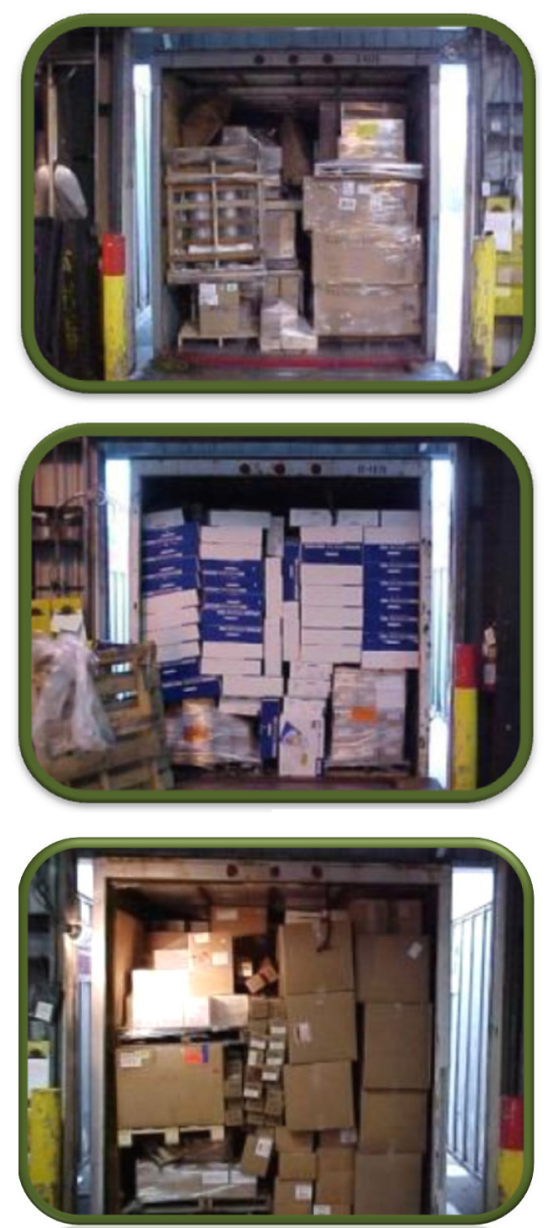

Figure 1: Loose and Unitized Freight Loading

to secure the cargo within. The intent is to ensure that cargo may not shift on or within, or fall from the commercial motor vehicle. This paper will discuss various methods used to prevent loads from falling as well as securement devices.

However, the above rules do not apply to the driver as stated "do not apply to the driver of a sealed commercial motor vehicle who has been ordered not to open it to inspect its cargo or to the driver of a commercial motor vehicle that has been loaded in a manner that makes inspection of its cargo impracticable."
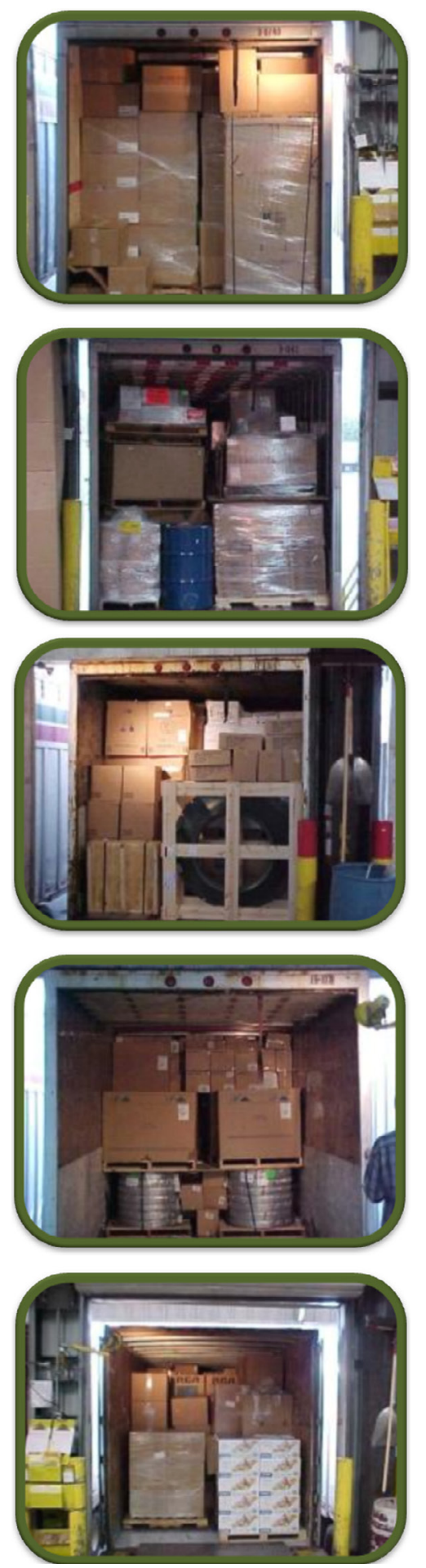

Figure 2: Unitized Freight Loading 


\subsection{REVIEW OF LOADED TRAILERS WITH MIXED FREIGHT}

The unique thing about the LTL or mixed load environment is that a carrier has no control over the type of freight leaving a terminal and going to a particular destination. They are dependent on what their customers provide them and must transport the freight quickly and safely through their distribution centers to the final destination. Thus, they are faced with the challenge of loading various types of freight, which are all packaged differently, together on one trailer, and then unloading it and reloading it with other freight, depending on the route the freight must take. Time is a critical component and any time a dock worker has to handle the freight manually, time is lost.

By studying the pictures provided in this section, it is apparent that the strength and protective capabilities of individual packages is critical, not only for the protection of the product, but facilitates loading with other freight. The trailers shown in Figure 1 have a large amount of boxed freight that is not unitized and must be stacked from floor to ceiling in order to provide space for other unitized freight. The loose boxes are probably loaded mechanically and manually depending on the size and weight of the freight. Figure 2 shows a variety of boxed freight that is unitized on pallets for easy handling and stowing. This type of freight assists the carrier in expediting their loading and unloading processes.

It is also important for the shipper to ensure that good quality pallets are used. A poor quality wood or plastic pallet that is not designed to carry the load and facilitate mechanical handling with fork lift trucks and pallet jacks can result in product damage or potential to injury. Additional load stabilization methods such as plastic stretch wrap, shrink wrap, plastic or metal bands, adhesives, stretch tape and nets, can facilitate additional securement and pro- vide stability to unitized freight. They also provide easy transfer of freight in cross-docking operations.

The examples discussed above show, comingled with the boxed freight, various crates and steel drums that contain larger products that are not able to utilize boxes and pallets. However, the crates, depending on their construction, are generally easier for a carrier to load freight adjacent to and on top of, rather than drums. A single drum can take up valuable space within a trailer and also cause handling restrictions when not tendered on a pallet.

From these examples it is also apparent how carriers attempt to utilize as much available space as possible. The general rule they try to follow is that they must cube-out the trailer, which means use all of the space available. A trailer with less void-space is more stable and will cause less shifting of freight, as opposed to one with lateral and longitudinal voids. Also carriers must keep in mind the weight of the load. Therefore, if they have large, heavy, dense freight, they are more likely to weight-out the trailer, which is regulated and mandated by the US DOT. In these conditions the load is more spread across the floor of the trailer to distribute it over the axles and wheels.

There are some general practices that have been developed by leading LTL freight carriers, based on their years of hauling cargo. Carriers have developed videos and training for their employees who are responsible top load trailers with mixed freight. These videos and recommended practices have been shown at leading packaging, transportation and handling conferences over the past two decades ${ }^{20}$.

Some of the safe loading and cargo securement methods are often thought of as "obvious". Some of 
the common methodologies used to train loaders of trailers are:

1. Large and heavy freight should be placed on the bottom.

2. If the trailer is partially loaded, a stair-case method may be used to step down the freight to the rear of the trailer.

3. Trailers should be loaded tight.

4. Void spaces should be avoided in both lateral and longitudinal directions inside closed van trailers or intermodal containers and box-cars. Use of additional devices such as wooden blocks, load bars, other freight, dunnage, airbags or friction rubber mats may be used based on industry standards that provide safe loading methods.

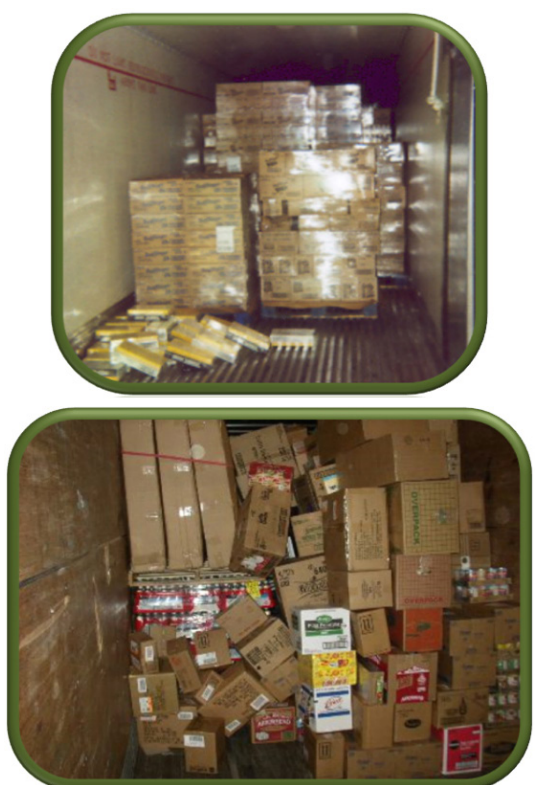

Figure 3: Shifted Mixed Freight Loads

Figure 3 shows examples of trailers with loaded mixed freight that has shifted and is not properly secured and can have potential for damage or injury.

It is important to understand that in general
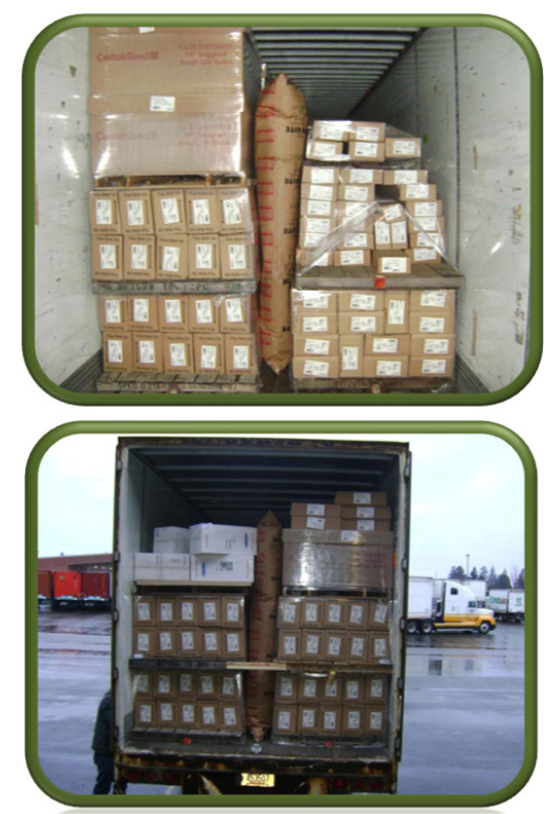

Figure 4: Properly Secured Loads
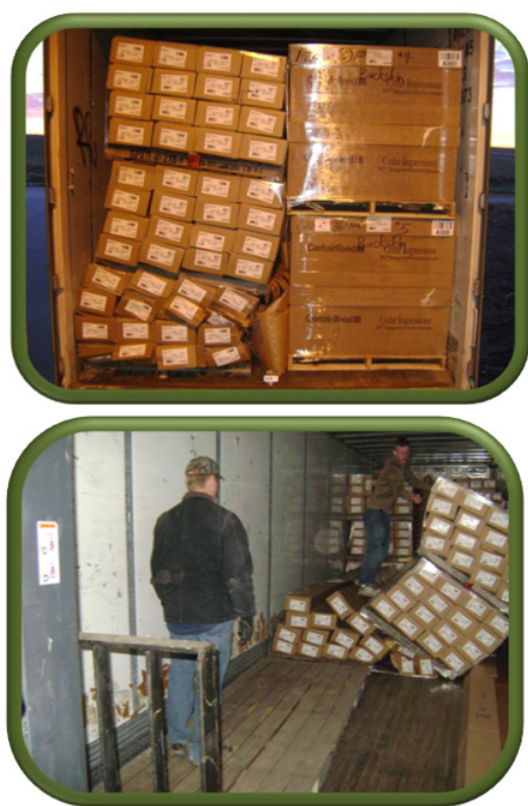

Figure 5: Improperly Secured Loads

most loads will shift to some degree due to the various movements that occur inside a trailer, railcar or intermodal container. The importance and need for proper load securement methods will prevent damage and potential injury to individuals handling 
products and packages during loading and unloading. Trailers shown in Figure 4 have a properly secured load inside a trailer using multiple methods including air bags, stretch wrap, tape, and wooden blocks. The mixed load does not optimize the space inside the trailer and with an absence of these securement methods, the products and packages would shift excessively resulting in damage and potential injury when the trailer doors are opened.

Figure 5 shows examples of similar loads as above but with extensive damage and shifting that occurred due to the absence of proper load securement. Heavier loads may require more and multiple methods for load securement. Industry groups like the Association of American Railroads develop loading guides that describe proper methods for loads to be placed inside railcars and intermodal trucks or containers to prevent damage to equipment or lading by using testing such as vibration suimulation and impact, and/or may conduct actual field shipment tests ${ }^{21}$. Similarly, the LTL industry has used sensors and video to monitor movement inside truck shipments with mixed loads and developed good safe proactices. Associations like ASTM $^{22}$ and ISTA ${ }^{23}$ also provide testing of such loads for truck and rail shipments.

\subsection{REDUCING DAMAGE DURING TRANSPORTATION USING LOAD SECUREMENT METHODS}

Shippers and carriers can use a range of different methodologies to secure loads inside containers, boxcars, and trailers. The Federal Motor Carrier Safety Regulations (FMCSR) requires that the load be safely secured during transportation ${ }^{24}$. It is therefore the responsibility of the carrier to ensure that the loads to be transported in their vehicles are properly secured so they do not pose a hazard to other vehicles and people using the same transport highway, rail track, or sea. The same obligation shifts to the manufacturer and shipper of the freight, if they prepare the packaging and load the products inside the trailer or container and apply a seal to the trailer before the carrier or its driver receives the authorization to move the filled trailer. Major retailers apply seals to vehicles such as truck trailers and intermodal containers to prevent pilferage and theft during transportation and therefore bear responsibility to secure the entire load for transportation.

In 2006, at the International Safe Transit Association annual education conference, Dow Chemical Company presented data on load securement or the lack thereof from a study done by Carolina Supply Chain Services, LLC ${ }^{25}$. The study had presented load unitization methods and securement of loads inside trailers for the grocery and food distribution industries. With respect to dunnage used for blocking and bracing loads inside trailers to prevent shifting of loads, the study found that nearly $48 \%$ of shipments had no stabilization device within the trailers. It also reported that an additional $7 \%$ of such devices failed when used.

Load stabilization devices in unitized/palletized loads include steel or plastic banding, corner posts, tie-sheets, plastic film stretch or shrink wrap that is properly wound around the load on a pallet or slip sheet, glues and adhesives, and netting and web products. The selection of a specific type or a combination of load stabilization methods can be determined by conducting pre-shipment tests using ISTA $^{23}$ and ASTM $^{22}$ methods.

Figure 6 shows the various types of dunnage and load securement methods used by the industry based on the study ${ }^{25}$. Approximately $44 \%$ of shipments in the food distribution used airbags, whereas another $8 \%$ used load bars or straps. 


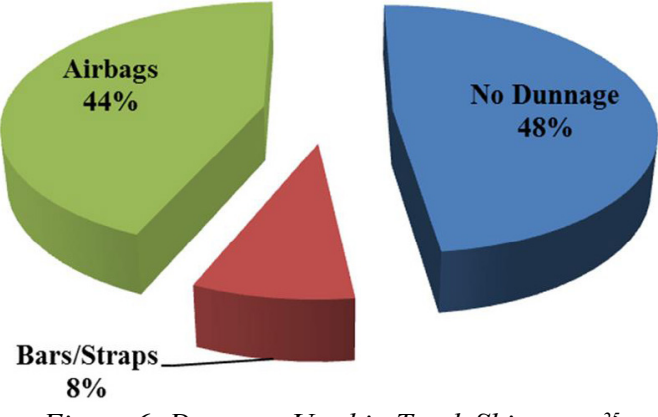

Figure 6: Dunnage Used in Truck Shipments ${ }^{25}$

Straps require trailers to have a strap securement method attached on the side walls of the trailer or container. Load bars can be applied inside any trailer or container to prevent loads from shifting and travelling to the rear doors when the trailer is in motion.

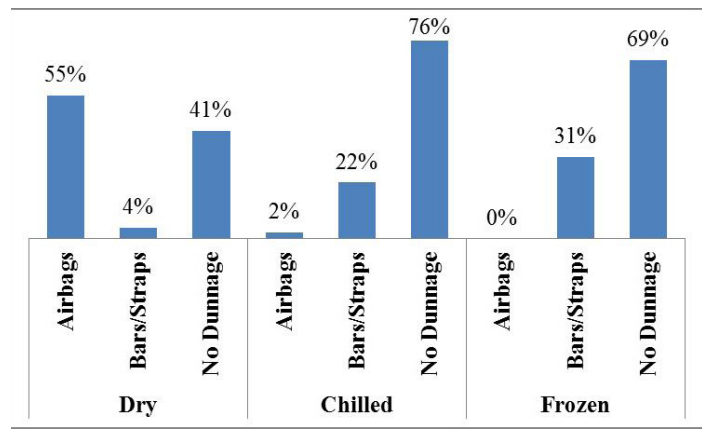

Figure 7: Load Securement Methods Used ${ }^{25}$

Figure 7 shows the break-down of load stabilization methods by the type of trailer (dry-van, refrigerated and frozen ${ }^{25}$. It is evident that dry van trailers prefer air bags over load bars as compared to refrigerated and frozen trailers due to prevent loads from being pushed to the sidewalls, that would prevent circulation and air flow between the perimeter of refrigerated or frozen trailers.

In terms of the overall unit load stabilization, the same study stated that nearly $14.20 \%$ of unit loads were not wrapped to the pallets (Figure 3 ) $^{25}$. In addition $8.94 \%$ of unit loads that had stretch-wrap applied, had wrap issues that would cause both insta- bility and result in damage to shipping units. Almost $39 \%$ of palletized loads did not optimize the pallet footprint. Recent studies on corrugated box performance have shown that overhang and poor pallet optimization can result in loss of strength in boxes creating damage and instability ${ }^{26,27}$. In addition to using stretch-wrap around the boxes or items to be unitized on a pallet, it is important that the stretch-wrap film be wrapped and tied to the pallet base.

Damage in shifting loads during severe accelerations or decelerations can cause the entire load to slide off a pallet surface. Plastic pallet surfaces are generally more slippery (due to a lower coefficient of friction) than wood pallets. However, plastic pallet manufacturers can use imprinted and indentation patterns on pallet top decks to create "stiction" between items and pallets. It is therefore important to tie the stretch film to the pallet base and the film be wrapped along with the pallet base and the lower items or packages. It also known that machine stretch-wrapped technology provides more consistent loads, that have an ability to apply pre-load and pre-stretch that keeps the film under tension over a longer period of time during transit.

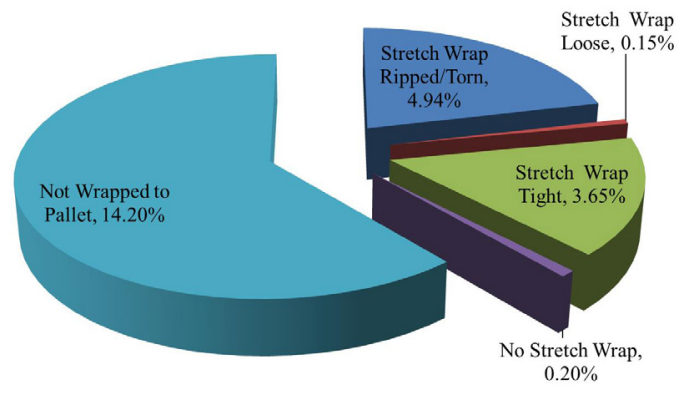

Figure 8: Issues with Loads Using Stretch Wrap as a Unitization Method ${ }^{25}$

Load securement inside a trailer, container or boxcar can be achieved by different means and depends on the mixture of products to be loaded, weight and volume of various packaged items, frictional properties of load with the vehicle floor, secondary de- 
vices such as plastic film stretch or shrink wraps, nylon or plastic straps, plastic or metal bands, steel chains, load bars, air-bags, nets, honeycomb, rubber mats, wood blocking and bracing and dunnage. Various manufacturers of cargo securement devices offer solutions based on the freight, and its weight and volume. It is also important to optimize the pallet footprint. Overhanging boxes or freight does not properly transfer the load to the pallet for even support and also create an easier potential for tip-over. Figure 9 shows the results from the same study ${ }^{25}$.

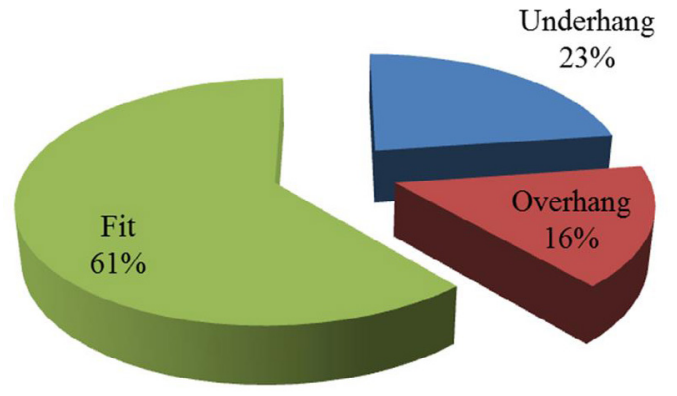

Figure 9: Pallet Surface Utilization ${ }^{25}$
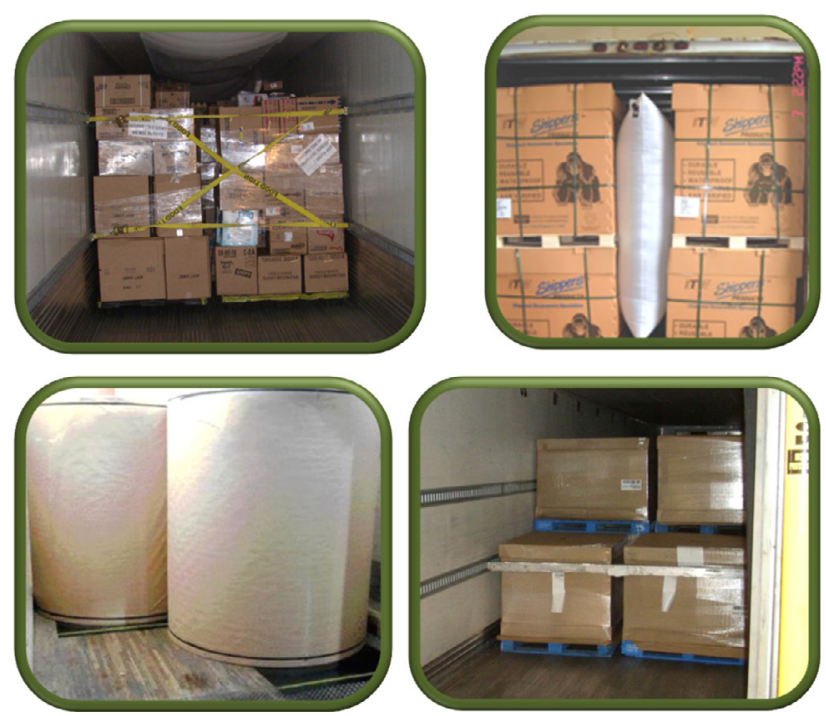

Figure 10: Typical Load Securement Methods in Trailers

Other types of load securement methods previously discussed are shown in Figure 10. These include load bars, stretch wrap, straps, air bags and friction rubber mats.

Proper use of plastic film stretch wrap is an effective load stabilization method ${ }^{28,29}$. As mentioned earlier it is important for a shipper to un-

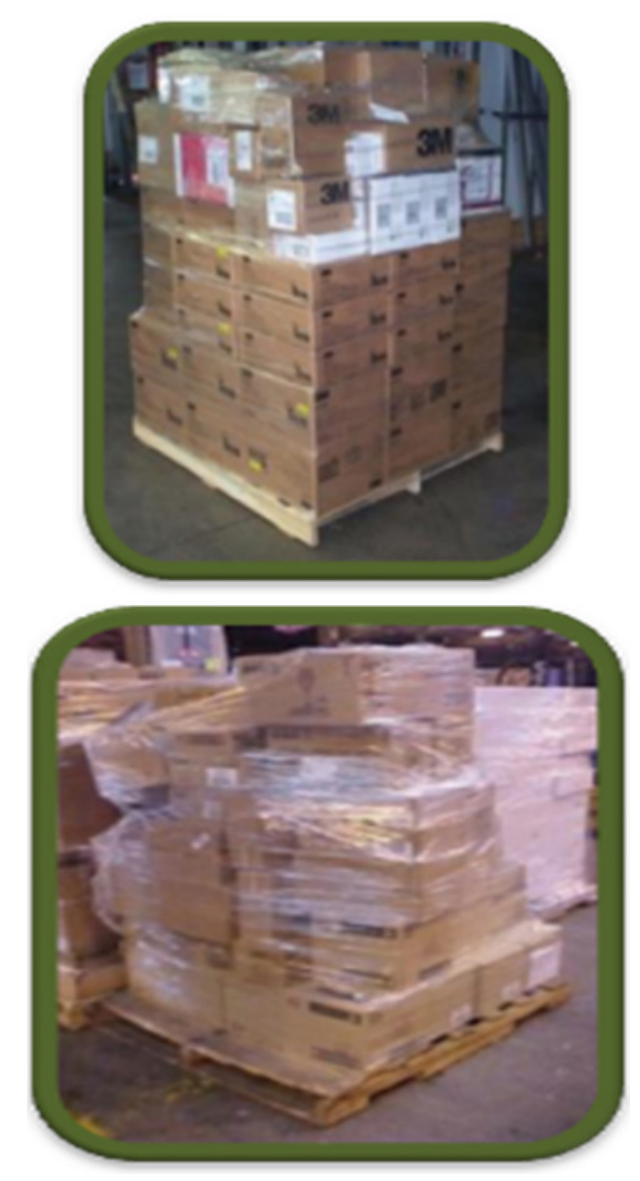

Figure 11: Unitization using Stretch Wrap

derstand the weight sizes and types of mixed loads to use appropriate amount of wrap with necessary tension and additives if long term and outside exposure is expected. Various types of plastics provide different mechanical properties and appropriate plastic stretch wrap materials can be selected based on the expected shipping and storage environment. Figure 11 shows application of stretch wrap to unitize and secure multiple boxes 
of varying size and weight on wooden pallets.

In the last decade a new method has been introduced to provide better features in securing odd shaped boxes and bags on to pallets. This method is called "stretch hood" where a

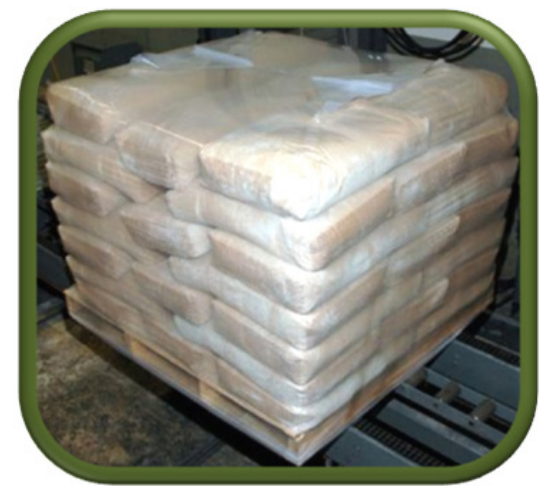

Figure 12: Stretch Hooded Unitized Load

large bag of plastic film is stretched and formed around a palletized load of products such as shown in Figure 12 for cement bags. It provides a more secure form of unitization compared to using traditional wrap-around stretch film method ${ }^{30}$.

\subsection{ROLE OF PALLETS IN SAFE TRANSIT AND HANDLING}

Pallets typically form the "tertiary" packaging component critical in developing a unitized load. Pallets provide a base for typical unit loads and aid in mechanical handling, transportation and

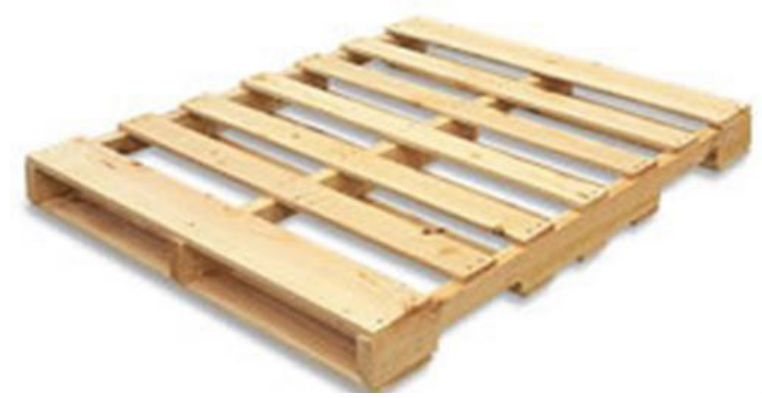

Figure 13: Stringer (left) and Block (right) Style Pallets storage of goods ${ }^{31}$. It is estimated that the materials handling industry in the US has approximately 2 billion pallets, made of various materials and in many forms, being used to store and move goods at any time ${ }^{32}$. The Grocery Manufacturer Association in the 1970's standardized pallets for the US retail industry to $48 \mathrm{x} 40$ inches that were mostly made of $\operatorname{wood}^{33}$. These pallets were mainly of a "stringer" design and therefore were not truly 4-way entry (Figure 13). Today, the majority of stringer pallets have a 4-way entry capability. Stringer pallets are largely used by US shippers, while block style pallets are predominant in EU.

In 2011, the Modern Material Handling conducted a major survey with its subscribers, and obtained over 650 qualified responses that addressed most of the recent trends ${ }^{34}$. Results showed that over $90 \%$ of respondents used wood as a pallet materials. Other materials being used for pallets included plastic, wood composite, paper cardboard/corrugated and metal (aluminum and steel). The three most important factors in making a decision for a pallet were found to be purchase price, strength and durability. An important observation in the survey ${ }^{34}$ was that there were a vast number of reused wooden and plastic pallets in the industry. However, in the past decade the price of good quality reusable pallets has gone up. Reusable pallets need to be inspected,

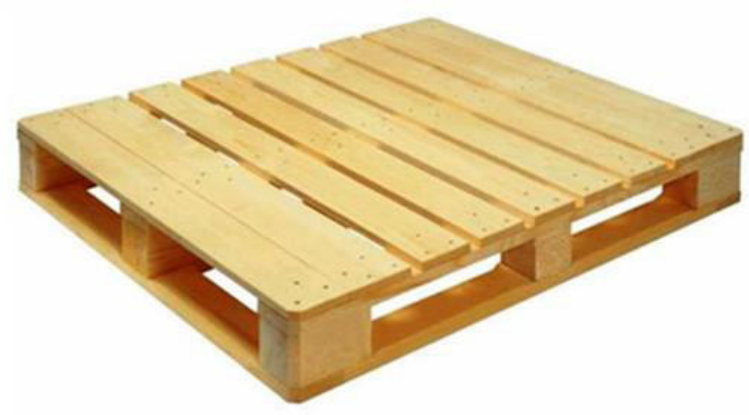


and rated for their strength before being used for a given application. They may also require additional treatments for specific applications in the food or pharmaceutical industry. A poor quality reusable wooden or plastic pallet can be a source of damage in shipment as well as a potential for injury when stacking loads or other empty pallets.

Figure 14 shows reusable wooden pallets with a considerable amount of damage incurred from previous shipments. It is clear that they range in size and quality. Good reusable pallet providers and leasing companies have practices that involve inspection repair and refurbishing of used pallets before they are put back in service. These pictures show some poor used wooden pallets that will most likely produce damage or have a risk of injury if used to ship or handle loads.

Extreme variations in size, quality, strength and durability of pallets received at a LTL terminal after shipments were delivered can be noticed in Figure 14. The far right image below shows an example of a poor strength reused wood pallet that failed in a LTL shipment due to weak deckboards.

\subsection{REGULATIONS \& PROCEDURES FOR SHIPPING HAZARDOUS MATERIALS}
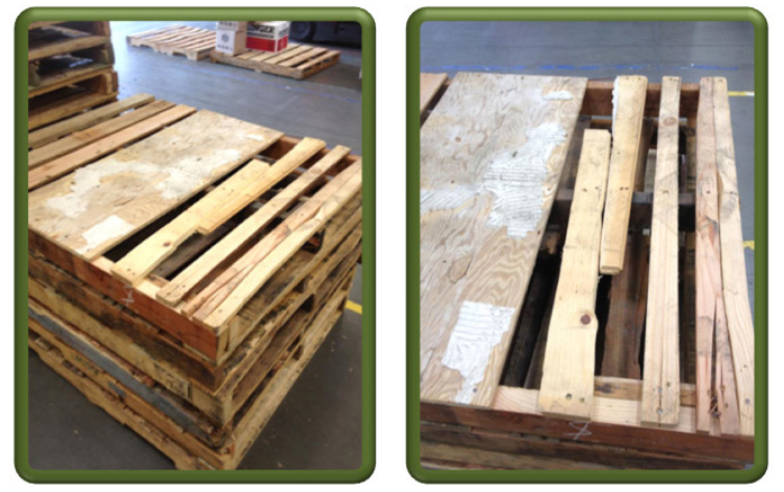

Figure 14: Damaged/Poor Strength Wooden Pallets
The regulations and procedures for shipping "hazardous" materials (HazMat) apply to all individuals involved with the transportation/shipping of hazardous materials ${ }^{24}$. This includes all those individuals who arrange for transport and/or may engage in any of the following activities involving hazardous materials: filling packages; marking and labeling packages; preparing shipping papers; handling, loading, securing and segregating packages within a transport vehicle, freight container or cargo hold; and transporting.

The U.S. Department of Transportation (DOT) enacts and enforces all HazMat transportation laws in the United States. Compliance with DOT regulations is a requirement for any person who offers a hazardous material for transportation. The hazardous materials shipper must meet the DOT's hazardous materials regulations (HMR), 49 CFR Parts 171-180. It is clear that the requirements for packaging labeling shipping and handling of hazardous materials is more stringent than most common consumer products, machinery and home building materials and supplies.

\subsection{SPECIFICATIONS FOR CORRUGATED BOXES}

Corrugated fibreboard boxes are the most commonly used form of shipping containers. They come in various sizes and shapes and can be both
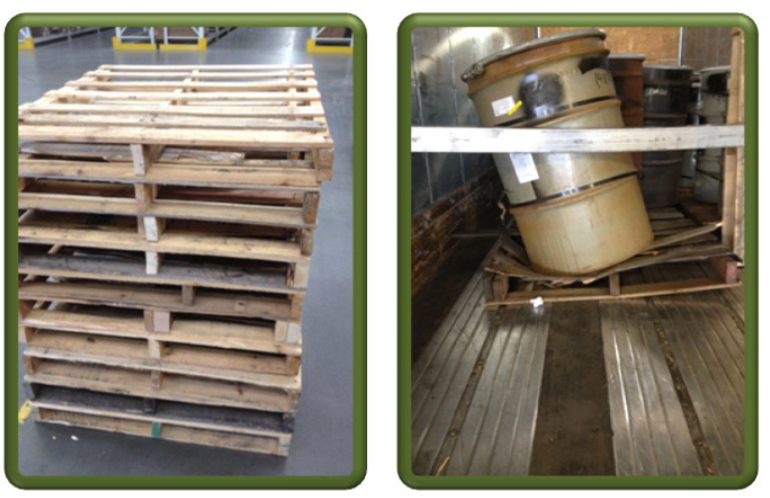
single-use and reusable based on the size and weight of the product. Internal dunnage or cushioning in conjunction with these shippers provides additional support, void-fill or attenuation from shock and vibration forces encountered during shipping and handling depending on material used for such purpose. The strength of the corrugated boxes can be tested but various factors such as physical (compression, vibration, drops, shocks, etc.) and climatic can lower the ultimate strength needed.

ASTM provides test methodologies for testing performance of shipping containers. Additionally, the Fibre Box Handbook, developed by corrugated materials and box manufacturers represented by the Fibre Box Association, provides additional resources on the selection of materials ${ }^{35}$. Additional test methods have also been developed by the International Organization for Standardization ${ }^{36}$ (ISO), Technical Association of Pulp and Paper Industries $^{37}$ (TAPPI) and ISTA ${ }^{23}$.

The strength of box is important in determining safe stacking and stability in both warehouse storage and shipping and stacking during transportation. Since paper is hygroscopic and highly sensitive to creep, it is important to test performance for the ultimate shipping and handling requirements based on industry accepted methods and test standards. Leading organizations like ASTM and ISTA provide such acceptable standards and test procedures based on input from academia, federal and governmental agencies and industry associations and representative members.

\subsection{CONCLUSIONS}

The paper and its discussion conclude the following:

- Securement of cargo and freight is required by legal regulations and is necessary to prevent damage and prevent accidents and injury to individuals handling loads.

- Packaging and loading methods are important in reducing damage and risk of injury during transportation and handling of LTL and mixed load shipments.

- LTL shipments must be properly blocked and braced with other packages or using load securement methods such as straps, retaining bars, air-bags, or dunnage.

- Loads will shift inside truck, rail and intermodal container shipments if void spaces exist after the loading process. Securement is therefore important to keep the load stable during transit and when loading and unloading freight.

- Packages, boxes and crates should be designed to permit top loading of lighter and smaller freight on top to optimize shipping densities. Failure to do this can result in tariff surcharges, damage or injury.

- It is critical to properly design pallets and use appropriate load unitization methods to keep loads stable when they are handled and transported. Reusable and repaired pallets must be inspected and insure that they can hold the required weight of future loads safely and provide safe interaction with material handling equipment.

- Palletized shipments require the product and packages to be secured to the pallet, and ensure that the pallet is of appropriate size and strength to keep the load stable during handling and transportation.

- Products shipped in the LTL environment should be packaged, at the very least, in compliance with the minimum packaging requirements set forth in the NMFC. These minimum requirements are set not only to protect the freight, but also to improve the safety for those who handle the freight, permit the 
carrier to expedite the distribution process, and make it easier for the carrier to handle and stow the freight on their docks and in their trailers.

- The LTL distribution environment is very unique in that a wide variety of commodities are handled numerous times and loaded on trailers with other freight that may or may not be compatible. The National Motor Freight Classification is an industry accepted freight classification standard that evaluates all commodities based on their transportability in order to compare different freight based on the same characteristics. Also, despite the NMFC's minimum packaging requirements, there are a variety of commodities that are inherently difficult to handle or stow, susceptible to damage, highly fragile, or problematic to develop packaging that is appropriate to adequately protect it from the rigors of this distribution environment.

\section{REFERENCES}

[1] Topper, E., Singh, S. P. and Singh, J. "Packaging Requirements for LessThan-Truckload Shipments to Reduce Damage-Machinery and Machine Parts, Doors and Windows and Miscellaneous Items". Journal of Applied Packaging Research, Vol. 5, No. 2, pp. 93-106, April 2011

[2] Topper, E., Singh, S. P. and Singh, J. "Packaging Requirements for LessThan-Truckload Shipments to Reduce Damage - Furniture, Appliances and Boxed Freight". Journal of Applied Packaging Research, Vol. 5, No. 1, pp. 43-56, January 2011
[3] Topper, E., Singh, S. P., Singh, J. "Packaging Requirements for Less-Than-Truckload Shipments to Reduce Damage - Paint, Televisions, and Copiers," Journal of Applied Packaging Research, Vol. 4, No. 2, April 2010

[4] Chonhenchob, V., Singh, S. P., Singh, J. J., Stallings, J. and Grewal, G. "Measurement and Analysis of Vehicle Vibration for Delivering Packages in Small-Sized and Medium-Sized Trucks and Automobiles." Journal of Packaging Technology \& Science; Vol. 25, pp. 31-38, 2012

[5] Singh, S. P., Singh, J., Saha, K., Church, E. "Measurement and Analysis of Vibration and Temperature Levels in Global Refrigerated Intermodal Container Shipments from South to North America along Atlantic Ocean." Journal of Applied Packaging Research, Vol. 6, No. 1, pp. 37-54, January 2012

[6] Singh, S. P., Saha, K., Singh, J. and Sandhu, A. P. S. "Measurement and Analysis of Vibration and Temperature Levels in Global Intermodal Container Shipments on Truck, Rail and Ship". Journal of Packaging Technology \& Science; Vol. 25, pp. 149-160, 2012

[7] Stallings, J., Singh, J., Singh, S. P. "Measurement and Analysis of Vehicle Vibration for Parcel Delivery Vehicles in Single Parcel Shipments," Journal of Applied Packaging Research, Vol. 4, No. 2, April 2010

[8] Chonhenchob, V., Singh, S. P., Singh, J., Sittipod, S., Swasdee, D., Pratheepthinthong, S. "Measurement and Analysis of Truck and Rail Vibration Levels in Thailand" Journal of Packaging Technology and Science. Volume 23, Issue 2, pages 91-100, March 2010 
[9] Singh, S. P., Singh, J, Stallings, J., Burgess, G., Saha, K. "Measurement and Analysis of Temperature and Pressure in High Altitude Air Shipments," Journal of Packaging Technology and Science. Vol. 23, Issue 1, pp. 35 - 46, December 2009

[10] Singh, S. P., Singh, J. , Chiang, K. C. , Saha, K. "Measurement and Analysis of "Small" Packages in Next Day Air Shipments" Journal of Packaging Technology and Science, Vol. 23, Issue 1, pp. 1 - 9, August 2009

[11] Singh, S. P., Singh, J., Kittipinyovath, P. "Measurement and Analysis of Shocks to Products Packaged in Pails in Single Parcel Ground Shipments" Journal of Packaging Technology and Science, Vol. 22, Issue 7, pp. 397 - 414, May 2009

[12] Singh, S. P., Singh, J., Gaur, P., Saha, K. "Measurement and Analysis of Vibration Levels on Warehouse and Retail Store Material Handling Equipment," Journal of Applied Packaging Research, Vol. 2, No. 2, December 2007

[13] Singh, S. P., Sandhu, A., Singh, J., Joneson, E. "Measurement and Analysis of Truck and Rail Shipping Environment in India," Journal of Packaging Technology and Science, Vol. 20, Issue 6, pp. 381 - 392, November/December 2007

[14] Rissi, G. O., Singh S. P., Burgess, G., Singh, J. "Measurement and Analysis of Truck Transport Vibration Levels in Brazil," Journal of Packaging Technology and Science, Vol. 21, Issue 4, pp. 231 - 246, October 2007
[15] Singh, J., Singh, P., Joneson, E. "Measurement and Analysis of U.S. Truck Vibration for Leaf Spring and Air Ride Suspensions and Development of Tests to Simulate these Conditions". Journal of Packaging Technology and Science, Vol. 19, Issue 6 , pp. 309 - 323, November/December 2006

[16] Singh, P., Burgess, G., Singh, J., Kremer, M. "Measurement and Analysis of the Next-day Air Shipping Environment for Mid-sized and Lightweight Packages for DHL, FedEx and United Parcel Service," Journal of Packaging Technology and Science, _Vol. 19, Issue 4, pp. 227 - 235, July/August 2006

[17] Pierce, S. and D. E. Young. Package Handling in Less-Than-Truckload Shipments: focused simulation measurement and test development, Proceedings of ISTA CON 98, International Safe Transit Association, East Lansing, MI, 1998.

[18] National Motor Freight Classification. What are Freight Classes? Accessed April 29, 2014 Link

[19] U.S. Government Printing Office, Electronic Code of Federal Regulations. Title 49 Transportation. Accessed April 29, 2014 Link

[20] Singh S. P. and E. Joneson. Video and Measurement of Dynamics of a Less than Truck Load Shipment. Proceedings of Dimensions 06, International Safe Transit Association, San Antonio, Texas, 2006.

[21] Association of American Railroads. Accessed April 29, $2014 \underline{\text { Link }}$

[22] American Society for Testing and Materials. Accessed April 29, $2014 \underline{\text { Link }}$

[23] International Safe Transit Association. Accessed April 29, $2014 \underline{\underline{\text { Link }}}$ 
[24] United States Department of Transportation, Federal Motor Carrier Safety Administration. Accessed April 29, 2014 Link

[25] Brooks, W. and M. Rawlins. Elemental to Stretch-hood Packaging, Unit Load and Shipment Stabilization Characteristics "An Independent Study Analysis, Unitizing, Pallet Quality and Shipping Unit Damages Analysis", Carolina Supply Chain Services, LLC and Dow Chemical Company, Dimensions 2006, International Safe Transit Association, East Lansing, MI 2006

[26] Singh, S. P., Singh, J. and Saha, K. "Effect of Palletized Box Offset on Compression Strength of Unitized and Stacked Empty Corrugated Fiberboard Boxes". Journal of Applied Packaging Research, Vol. 5, No. 3, pp. 157-168, July 2011.

[27] Singh, J., Singh, S. P. and Saha, K. "Effect of Horizontal Offset on Vertical Compression Strength of Stacked Corrugated Fiberboard Boxes". Journal of Applied Packaging Research, Vol. 5, No. 3, pp. 131-144, July 2011.

[28] Singh, J., Cernokus, E., Saha, K. and Roy, S. "The Effect of Stretch Wrap Pre-Stretch on Unitized Load Containment.” Journal of Packaging Technology \& Science. DOI: $10.1002 /$ pts.2083

[29] Singh, J.*, Blumer, T., Roy, S. and Saha, K. "Carton Clamp Test Methodologies and the Effects on Load Containment and Retention." Journal of Packaging Technology \& Science. DOI: $10.1002 /$ pts.2080

[30] Hausmann, K. "Permanent antistatic agent offers long term performance for films and containers." Plastics, Additives and Compounding 9.3 (2007): 40-42.
[31] Weigel, T. G. and White, M. S. (1999), The effect of pallet connection stiffness, deck stiffness and static load level on the resonant response of pallet decks to vibration frequencies occurring in the distribution environment. Packag. Technol. Sci., 12: 47-55

[32] Rogers, L. K. Reader Survey: Pallet usage on the rise. October 2011, Modern Materials Handling

[33] Twede, Diana, Diane Mollenkopf, and Cristina Guzman-Siller. "A MarketDriven Investigation of Pallet Trends in Grocery Chains." Journal of food distribution research 38.1 (2007).

[34] Trebilcock, B., The pulse on pallets, Modern Material Handling, November, 2012.

[35] Fibre Box Association. Accessed April 29, $2014 \underline{\text { Link }}$

[36] International Organization for Standardization. Accessed April 29, $2014 \underline{\text { Link }}$

[37] Technical Association of Pulp and Paper Industries. Accessed April 29, 2014 $\underline{\text { Link }}$ 